\title{
Günlük Ortalama Adım Sayısının Denge, Esneklik ve Reaksiyon Zamanı Üzerine Etkisi
}

The Effect of Daily Average Number of Steps on Equilibrium, Flexibility and Reaction Time

Çetin SAYACA ${ }^{1}$, Aykut KARAMAN ${ }^{2}$

1 Öğr. Gör. Dr., Bursa Uludağ Üniversitesi Sağlık Bilimleri Fakültesi Fizyoterapi ve Rehabilitasyon Bölümü, Bursa, Türkiye

${ }^{2}$ Uzm. Fzt., Malatya İI Spor Müdürlüğü, Malatya, Türkiye

\section{ÖZ}

Amaç: Bu çalışma, sağlıklı bireylerde günlük ortalama adım sayısının denge, alt ekstremite kas esnekliği ve ayak reaksiyon zamanı ile ilişkisini araştırmak amacıyla planlandı. Gereç ve Yöntem: Çalışmaya yaş ortalaması 25,15 $\pm 4,85$ yıl olan 54 sağlıklı birey (19 kadın, 35 erkek) dahil edildi. Çalışmaya katılan bireylerin demografik özellikleri kaydedildikten sonra, günlük adım sayısını belirlemek amacıyla bireylere pedometre cihazı verilerek bir hafta boyunca üzerlerinde taşımaları istendi. Dinamik denge Y denge testi, statik denge flamingo denge testi, esneklik otur-uzan esneklik testi, reaksiyon zamanı Nelson ayak reaksiyon testi ile değerlendirildi. Sonuçlar: Günlük ortalama adım sayısı ile alt ekstremite kas esnekliği, reaksiyon zamanı, statik denge ve dinamik denge arasında ilişki bulunamadı ( $p>0,05)$. Tartışma: Günlük ortalama adım sayısı esneklik, denge ve reaksiyon zamanını etkilememektedir. Günlük ortalama adım sayısından çok yürüme aktivitesinin yoğunluk ve süresi esneklik, denge ve reaksiyon zamanı üzerine olumlu etkileri olabilir.

Anahtar Kelimeler: Yürüyüş; Esneklik; Postural Denge.

\section{ABSTRACT}

Purpose: This study was planned to investigate the relationship between the average number of daily steps in healthy individuals with balance, lower extremity muscle flexibility and foot reaction time in healthy individuals. Material and Methods: Fifty-four healthy individuals (19 females, 35 males) with a mean age of $25.15 \pm 4.85$ years were included in the study. After the demographic characteristics of the participants were recorded, the individuals were given a pedometer device to determine the number of daily steps and were asked to wear them for a week. Dynamic balance with $\mathrm{Y}$ balance test, static balance with flamingo balance test, the flexibility of lower limb muscles with sit and reach test, and reaction time with Nelson foot reaction test was evaluated. Results: No relation was found between the average number of daily steps and flexibility of lower limb muscles, reaction time, static balance, dynamic balance $(p>0.05)$. Discussion: The average number of daily steps was not found to affect flexibility, balance and reaction time. The intensity and duration of walking activity rather than the average number of steps per day can have positive effects on flexibility, balance and reaction time.

Keywords: Gait; Flexibility; Postural Balance. 
Fiziksel aktivite, iskelet kaslarının kullanılması sonucu enerji harcamayı gerektiren tüm hareketler olarak tanımlanmaktadır (Arslan, Aras ve Can, 2016). Gün geçtikçe fiziksel aktivitenin önemi daha da anlaşılmakta ve devletler tarafından da sağlık politikası olarak desteklenmektedir (Yıldırım, Yıldırım ve Eryılmaz, 2019). Fiziksel aktivitenin kas gücü, denge, esneklik, postür, reaksiyon zamanı ve motor becerilerin gelişimi üzerine olumlu etkileri vardır (Eren, Müniroğlu ve Özer, 2017).

Yürüyüş, günümüzde en sık kullanılan fiziksel aktivite türüdür (İri, Ersoy, İri, 2010). Günlük ortalama 4000 adımın fiziksel aktivite intiyacını karşılayabileceği, bunun ise 30 dakikalık bir yürüyüşe denk olduğu (Welk, Differding, Thompson ve ark., 2000), günlük ortalama 10000 adım atmanın 30 dakikalık fiziksel aktiviteye eşdeğer olduğu belirtilmektedir (Jordan ve Jurca, 2005; Hultquist ve Albright, 2005). Literatürde, Fiziksel aktivitenin sistemik (dolaşım, solunum, kas, kemik vb.) faydalarının dışında denge (Sarıkaya ve İnan, 2014; Ardıç, 2014), esneklik (Ardıç, 2014) ve reaksiyon zamanını (Arabacı, 2008) üzerine olumlu etkileri olduğu bilinmektedir. Ancak 30 dakika ve üzeri sürelerde düzenli yapılan yürüyüşler dışında günlük yaşam aktiviteler sırasında elde edilen günlük adım sayısının denge, esneklik ve reaksiyon zamanı üzerine etkisi bilinmemektedir. Bu çalışma, günlük adım sayısının denge, esneklik ve reaksiyon zamanı üzerine etkisini araştırmak amacıyla planlanmıştır. Çalışmamızın hipotezleri; (1) günlük adım sayısı ile denge arasında bir ilişki vardır, (2) günlük adım sayısı ile alt ekstremite kas esnekliği arasında bir ilişki vardır, (3) günlük adım sayısı ile ayak reaksiyon zamanı arasında bir ilişki vardır.

\section{GEREÇ VE YÖNTEM}

Gözlemsel bir araştırma olarak planlan bu çalışmaya girişimsel olmayan klinik araştırmalar etik kurulu tarafından onay alındıktan sonra başlanıp Helsinki Bildirgesi'nin etik yönerge ve ilkelerine göre yürütülmesine özen gösterildi. Tüm bireyler, değerlendirme öncesinde çalışmanın kapsamı ve izlekler hakkında bilgilendirildikten sonra çalışmaya özel olarak hazırlanmış bilgilendirilmiş gönüllü olur formunu imzaladılar.

Çalışmaya, yaş aralığı 20 ilâ 40 yıl ve vücut kütle indeksi 18 ilâ 29,9 kg/m2 arasında olan bireyler dahil edilirken flamingo denge testinde 15 ve üzeri hata yapan, haftada en az iki kez otuz dakika ve üzeri fiziksel aktivite yapan, kronik ve sistemik rahatsızlığı (Diyabetes Mellitus, Hipertansiyon, Romatoid Artrit vb.) olan, alt ekstremite cerrahisi geçirmiş, alt ekstremiteye ait herhangi bir ağrısı olan, nörolojik ve/veya psikiyatrik ve/veya tümöral hastalık tanısı olan bireyler ise dahil edilmedi.

\section{Veri Toplama Araçları}

Çalışmaya katılan bireylerin demografik özellikleri kaydedildikten sonra değerlendirme öncesi ısınma amacıyla 5 dakika hafif tempoda nefes nefese kalmadan koşu yapmaları istendi. Baskın taraf alt ekstremitelerini belirlemek amacıyla top önünde çift ayak yerde beklerken topa vurmaları istendi. Topa vurdukları taraf, alt ekstremite için baskın taraf olarak kaydedildi (Kutlu ve Karadağ, 2003).

Günlük ortalama adım sayısının hesaplanması: Çalışmaya katılan bireylerin günlük atılan adım sayısını belirlemek amacıyla pedometre (Omron HJ-320-E, Manheim, Deutschland) kullanıldı. Çalışmaya katılan tüm bireylere pedometrenin nasıl çalıştığı öğretildi. Tüm bireylerden pedometreyi bir hafta boyunca sabah kalkar kalkmaz takmaları ve gece yatana kadar da tuvalet, banyo gibi özel alanlar haricinde kullanmaları istendi. Bir hafta sonucundaki toplam adım sayısı yediye bölünerek günlük adım sayısı kaydedildi (Ersoy, 2008). Esnekliğin Değerlendirmesi: Gastrocnemius, hamstring ve lumbal kas gruplarının esnekliklerini ölçmek amacıyla otur-uzan esneklik testi kullanıldı. Bu test için $15 \mathrm{~cm}$ 'si öne çıkıntı yapan $35 \mathrm{~cm}$ uzunluğunda ve 32 cm yüksekliğinde bir adet sehpa kullanıldı. Değerlendirmeye alınan tüm bireylerden ayakkabılarını çıkararak yere serilmiş egzersiz matı üzerinde uzun oturur pozisyonunda ayak tabanlarını sehpaya temas edecek ve dizleri düz pozisyonda kalacak şekilde yerleştirerek sehpanın üzerinden mümkün olduğu kadar ileriye doğru uzanmaları istendi. Parmaklarının uzandığı en uç nokta da 2 saniye bekledikten sonra ayaklarının dayandığı seviye ile uzandıkları mesafe arası cm. cinsinden ölçülerek kaydedildi. Test üç defa tekrar edilerek uzanılan en uzak mesafe $\mathrm{cm}$. olarak çalışmaya dahil edildi (Hazar ve Taşmektepligil, 2008). Reaksiyon Hızının Değerlendirmesi: Reaksiyon hızını değerlendirmek amacıyla Nelson Ayak Reaksiyon Testi kullanıldı. Bireylerden ayakkabılarını çıkartmaları ve tabureye oturmaları istendi. Baskın taraf ayakucu duvardan $2,5 \mathrm{~cm}$ ve topuğu ise $5 \mathrm{~cm}$ uzaklıkta olacak şekilde pozisyonlandı. Gözlemci, $30 \mathrm{~cm}$ uzunluğundaki tahta cetveli duvar üzerinde ve değerlendirilecek bireyin baskın taraf ayak başparmak ucu hizasında tuttu. Üçten geriye doğru, birer birer sayıp sıfır dediğinde cetvel bırakıldı. Bireyden, düşen cetveli ayakucu ile tutması istendi. Cetveli yakaladığı andaki ayakucunun üzerindeki değer santimetre cinsinden kaydedildi. Test 
5 kez tekrarlandı. En düşük ve en yüksek değer dışında kalan 3 değerin ortalaması alınarak santimetre cinsinden kaydedildi. Elde edilen ortalama değer "Reaksiyon Zamanı $=\sqrt{ } 2 \times$ Mesafe $(\mathrm{cm}) / 980 \mathrm{~cm} / \mathrm{sn} 2$ " formülüne konularak reaksiyon zamanı saniye cinsinden hesaplanarak kaydedildi (Tamer, 2000).

Statik Dengenin Değerlendirilmesi: Statik dengeyi değerlendirmek amacıyla flamingo denge testi kullanıldı. Test için tahta bir kiriş ve süreyi tutmak için de süreölçere intiyaç vardır. Bireyler baskın alt ekstremitesi ile tahta kiriş üzerinde dengesini sağladıktan sonra süreölçer çalıştırıldı. Baskın olmayan ayağını aynı taraf eliyle tutması istendi. Dengesinin bozularak pozisyonunu koruyamaması ve ayağının yere değmesi hata kabul edilip süreölçer durduruldu. Test pozisyonuna geri dönülerek süreölçer kaldığı zamandan tekrar başlatıldı. Kişinin bir dakika içerisinde yaptığı hata sayısı kadar puan verilerek kaydedildi. Bir dakika içerisinde 15 ve üzeri hata yapan bireyler çalışmaya dahil edilmedi (Hazar ve ark., 2008).

Dinamik Dengenin Değerlendirilmesi: Dinamik dengenin değerlendirilmesi amacıyla $Y$ Denge Testi (Modified Star Excursion Test, SEBT) kullanıldı. $Y$ denge testinin yapılacağı zemin üzerine üç adet bir buçuk metre uzunluğundaki mezuralar yere anterior ile posteromedial ve posterolateral mezuralar arasında $135^{\circ}$ lik; posteromedial ve posterolateral mezuralar arasında ise $90^{\circ}$ lik açı olacak şekilde yapıştırıldı. Çalışmaya katılan bireylerden bu üç mezuranın kesişme noktasına baskın taraf alt ekstremiteleri üzerinde durarak baskın olmayan taraf ayakucuyla yere temas ettirmeden anterior, posteromedial ve posterolateral yönlere uzanması istendi. Test sırasında bireyin baskın taraf topuğunun yerden kalkmamasına, dengesini kaybetmeden ve havadaki ayağını yere değdirmeden başlangıç pozisyonuna gelmesine dikkat edildi. Değerlendirme her yöne üç kez tekrarlandı ve aynı yöndeki uzanımların ortalaması alınarak kaydedildi (Gribble ve Hertel, 2003). Alt ekstremite uzunluk farkının etkisini ortadan kaldırmak için alt ekstremite uzunluğu ölçüldü. Bireylerin baskın tarafta yer alan spina iliaca anterior superioru ile aynı taraf medial malleol arasındaki uzaklık mezura ile $\mathrm{cm}$ cinsinden ölçülerek kaydedildi (Erdoğan, Dal, Maraşlıgil ve ark., 2016). Her üç yönde değerlendirilen dinamik denge sonuçlarının ortalama skorunu hesaplamak amacıyla "Ortalama Skor= (anterior + posteromedial + posterolateral) / (3 x bacak uzunluğu uzunluğu) x 100" formülü kullanılarak normalizasyonu hesaplandı (Shaffer, Teyhen, Lorenson ve ark., 2013).

\section{Istatistiksel Analiz}

Çalışmadan elde edilen veriler IBM-SPSS programı 20. versiyon yazılımı kullanılarak analiz edildi (IBM Corp., Armonk, New York, United States). Sayısal verilerin normal dağılımları Kolmogorov-Smirnov testi ve görsel yöntemler (Histogram) kullanılarak değerlendirildi. Sayısal verilerin dağılımları analiz edildiğinde adım atma sayısının, reaksiyon hızının, esneklik test sonucunun ve dinamik denge ortalama skorunun normal dağıldığı saptandı. Normal dağılan sayısal veriler arasındaki ilişki Pearson korelasyon analizi ile değerlendirildi. Statik denge ile adım atma sayısı, reaksiyon hızı, esneklik test sonucu ve dinamik denge ortalama skoru arasındaki ilişkinin değerlendirilmesinde ise Spearman korelasyon analizi kullanıldı. Korelasyon katsayısı 0,30 ile 0,39 arasında zayıf düzeyde ilişki, 0,40 ile 0,59 arasında orta düzey ilişki, 0,60 ila 0,69 arasında iyi düzeyde ilişki, 0,70 ila 0,75 arasında çok iyi düzeyde ilişki ve 0,75-1,00 arasında yüksek düzeyde ilişki olduğunu gösterir. Anlamlılık düzeyi $p<0,05$ olarak kabul edildi.

\section{SONUÇLAR}

Çalışmaya katılan 54 bireyin (19 kadın, 35 erkek) yaş ortalaması 25,15 $\pm 4,85$ yıl, vücut kütle indeks ortalaması 23,04 $\pm 2,97 \mathrm{~kg} / \mathrm{m} 2$ idi. Bireylerin ortalama adım sayısı, denge, esneklik ve reaksiyon zamanına ait tanımlayıcı bilgiler Tablo 1'de verilmiştir. Günlük ortalama adım sayısı ile esneklik, reaksiyon zamanı, statik denge ve dinamik denge arasındaki ilişki Tablo 2 'de verilmiş olup günlük ortalama adım sayısı ile esneklik, reaksiyon zamanı, statik denge ve dinamik denge arasında bir ilişki bulunamamıştır $(p>0,05)$.

Tablo 1. Çalışma ile ilgili değerlendirme parametrelerine ait ortalama ve minimum maksimum değerleri.

\begin{tabular}{lcc}
\hline & Ortalama \pm SS & Minimum-Maksimum \\
\hline Günlük ortalama adım sayısı (adım) & $7887,000 \pm 3881,802$ & $1928-19221$ \\
\hline Esneklik (cm) & $16,870 \pm 7,743$ & $2-33$ \\
\hline Reaksiyon zamanı (sn) & $0,021 \pm 0,008$ & $0,004-0,039$ \\
\hline Statik denge (hata sayısı) & $4,351 \pm 3,198$ & $0-12$ \\
\hline Ortalama dinamik denge skoru (puan) & $118,670 \pm 19,107$ & $80,068-157,489$ \\
\hline
\end{tabular}


Tablo 2. Günlük ortalama adım sayısı ile esneklik, reaksiyon zamanı, statik denge ve dinamik denge arasındaki ilişkinin incelenmesi

\begin{tabular}{lcccc}
\hline & Esneklik & $\begin{array}{c}\text { Reaksiyon } \\
\text { Zamanı }\end{array}$ & $\begin{array}{c}\text { Statik } \\
\text { Denge }\end{array}$ & $\begin{array}{c}\text { Ortalama Dinamik } \\
\text { Denge Skoru }\end{array}$ \\
\hline Günlük Ortalama Adım Sayısı & $\mathrm{r}: 0,036$ & $\mathrm{r}:-0,119$ & $\mathrm{r}: 0,177$ & $\mathrm{r}: 0,195$ \\
& $\mathrm{p}: 0,794^{\alpha}$ & $\mathrm{p}: 0,393^{\alpha}$ & $\mathrm{p}: 0,201^{*}$ & $\mathrm{p}: 0,158^{\alpha}$
\end{tabular}

${ }^{\alpha}:$ Pearson korelasyon testi; ${ }^{\ddagger}:$ Spearman korelasyon testi; $p<0,05$.

\section{TARTIŞMA}

$\mathrm{Bu}$ çalışma, sağlıklı bireylerde günlük ortalama adım sayısı ile esneklik, reaksiyon zamanı ve denge arasında ilişkiyi araştırmak amacıyla yapıldı. Çalışma sonucunda, sağlıklı bireylerde günlük ortalama adım sayısı ile esneklik, reaksiyon zamanı ve denge arasında ilişki olmadığı saptandı.

Fiziksel aktivite seviyesi, teknolojik gelişimlere paralel olarak her geçen gün azalmaktadır. Fiziksel aktivite sistemler (dolaşım, solunum, kas, kemik vb.), denge (Sarıkaya ve ark., 2014; Ardıç, 2014), esneklik (Ardıç, 2014), reaksiyon zamanını (Arabacı, 2008), kas gücü, denge, esneklik, postür, reaksiyon zamanı ve motor becerilerin gelişimi üzerine olumlu etkileri olduğu bilinmektedir (Eren ve ark., 2017). Sağlığın korunması için de devletler tarafından desteklenen temel konuların başında gelmektedir (Yıldırım ve ark., 2019). Günümüzde fiziksel aktiviteler içerisinde en sık kullanılan ve tavsiye edilen aktivite türü yürüyüştür (İri ve ark., 2010). Ayrıca, sağlıklı bireylerin de fiziksel aktivite olarak yürüyüşü sıklıkla tercih ettikleri görülmektedir (Arslan, Alemdaroğlu, Öksüz ve ark., 2018).

Günlük ortalama 7.500 adım atmanın sağlıklı yaşamın bir gereği olarak kabul edilirken 10 bin adımdan fazla adım atmanın ise yüksek fiziksel aktivite olarak kabul edilmektedir (Mantovani, Duncan, Codogno ve ark., 2016). Bu çalışmaya katılan bireylerin günlük ortalama adım sayıları açısından incelendiğinde fiziksel aktivite düzeylerinin "biraz aktif" sınıfında yer aldıkları görülmektedir (Tudor-Locke ve Bassett, 2004). Bu ortalama adım sayısı sağlıklı yaşam için gerekli olan ortalama adım sayısını sağlamaktadır (Mantovani ve ark., 2016). Bu açıdan çalışmaya katılan bireylerin günlük ortalama adım sayısı açısından incelendiğinde literatürde tavsiye edilen ortalama adım sayısını karşıladığı görülmektedir. Fiziksel aktivitenin kas gücü, denge, esneklik, postür, reaksiyon zamanı ve motor becerilerin gelişimi üzerine olumlu etkileri olduğu bildirilmektedir (Eren ve ark., 2017). Fiziksel aktivite düzeyinin denge üzerine olumlu etkileri olduğunu bildiren çalışmalar (Sarıkaya ve ark., 2014; Ardıç, 2014) olmasına rağmen sağlıklı genç bireylerde fiziksel aktivite düzeyi ile statik denge arasında herhangi bir ilişki olmadığını gösteren çalışmalarda vardır (Karaman, Özden, Özcanlı ve ark., 2020). Fiziksel aktivite düzeyi ile esneklik arasında pozitif yönlü bir ilişki olduğu (Mikkelsson, Nupponen, Kaprio ve ark., 2006), fiziksel aktivite düzeyi artıkça da esnekliğin arttığı (Düzgün ve Baltacı, 2009), ancak yavaş yürüyüş gibi düşük enerji seviyesine sahip fiziksel aktivitelerin ise esneklik üzerine olumlu etkileri olmadığı belirtilmektedir (Manire, Kipp, Spencer ve ark., 2010). Reaksiyon zamanı, reseptörlerden gelen bilginin merkezi sinir sisteminde değerlendirilerek kas aktivitesini meydana geldiği bir süreçtir (Guyton ve Hall, 2006). Fiziksel aktivite, reaksiyon zamanını olumlu etkileyerek tepki süresini kısalttığı ve performansta artışa sebep olduğu belirtilmektedir (İri ve ark., 2010; Arabacı, 2008). Yürüyüş, günümüzde en sık kullanılan fiziksel aktivite türü olması (İri ve ark., 2010) ve fiziksel aktivitenin denge, esneklik ve reaksiyon zamanı üzerine olumlu etkileri düşünüldüğünde yürüyüşün de bu parametreleri olumlu etkilemesi beklenmektedir. Ancak, bu çalışma sonucunda, beklenenin aksine günlük ortalama adım sayısı ile denge, esneklik ve reaksiyon zamanı arasında herhangi bir ilişki olmadığı saptandı. Bu çalışmaya katılan bireylerin günlük ortalama adım sayısı sağlıklı yaşamın bir gereği olarak kabul edilen ortalama adım sayısı olan 7.500 adımın üzerinde idi (Mantovani ve ark., 2016). Literatürde belirtildiğinin aksine yürüyüşün denge, esneklik ve reaksiyon zamanı üzerine olumlu etkilerinin günlük ortalama adım sayısından daha çok egzersizin hızı, süresi, frekansı vb. parametreleri daha fazla etkiliyor olabilir. Özellikle sağlıklı genç bireylere, yürüyüş olarak fiziksel aktivite planlanırken, egzersiz reçetesinde, ortalama adım sayısının birincil olarak ön planda tutulmaması gerektiği düşünülmektedir. Daha fazla örneklem üzerinde egzersizin yüklenme, ilerleme, yoğunluk ve özelleşme prensiplerinin de ele alınarak yapıldığı çalışmaların bu konuyu aydınlatmada daha faydalı olabileceğini 
düşünmekteyiz.

Literatürde, yürüyüş ile ilgili araştırmalara bakıldığında en sık konu olan parametrenin adım sayısı olduğu görülmektedir (Jordan ve ark., 2005; Hultquist ve ark., 2005; Ersoy, 2008; Mantovani ve ark., 2016). Günlük adım sayısının artırılması sağlıklı yaşam için en güvenilir yöntemlerden biri olarak kabul edilmektedir (Tudor-Locke, Craig, Brown ve ark., 2011). Adım sayısının artması ile inaktivite sonucu ortaya çıkan kan basıncında ve kiloda artma, kardiovasküler hastalıklar, diyabet, kanser, osteoporoz, hipertansiyon ve depresyon gibi kronik hastalıkların olumsuz etkilerinin önüne geçilebileceği gösterilse de (Bravata, SmithSpangler, Sundaram ve ark., 2007; Tunçay ve Yeldan, 2013) yaralanmalardan korunmada ve sağlıklı yaşamda önemli bir yeri olan denge, esneklik ve reaksiyon zamanı gibi önemli parametreleri olumlu etkileyebilmesi için gerekli tek parametre olmadığı bu çalışma sonucunda görülmektedir. Herhangi bir egzersiz programının başarılı olabilmesi için egzersizin yüklenme, ilerleme, yoğunluk, adaptasyon, geri dönüşebilme, iyileşme ve özelleşme prensiplerine de uyması gerekir (McArdle, Katch ve Datch, 2006). Bu açıdan, yürüyüş ile ilgili sadece adım sayısına odaklanmaktan öte egzersiz ile ilgili diğer parametrelerin de birlikte ele alındığı, bütüncül bir egzersiz reçetesi ile sağlığın korunması amaçlanmalıdır.

Bu çalışmanın bazı kısıtlılıkları bulunmaktadır. En önemli kısıtlılığı günlük yürüyüşlerde kesintisiz olarak yapılan yürüme hızı ile süresinin, adım sayısı ile birlikte kaydedilmemesidir. Bu parametrelerin birlikte değerlendirilip, analiz edilmesi ile adım atma sayısının gerçek etkisi gözlemlenebilirdi. Bir diğer kısıtılık ise, cinsiyetin araştırılan parametreler üzerindeki olabilecek etkisidir. Çalışmaya, her iki cinsiyetten eşit sayıda birey dahil edilebilir ya da her iki cinsiyet üzerinde ayrı ayrı çalışmalar planlanabilir.

Günlük ortalama adım sayısı ile denge, alt ekstremite kas esnekliği ve ayak reaksiyon zamanı arasında herhangi bir ilişki bulunamadı. Fiziksel aktivite olarak önerilen yürüyüşün önemli bir parametresi olan günlük ortalama adım sayısının tek başına alt ekstremite kas esnekliği, denge ve ayak reaksiyon zamanı üzerinde etkili olmadığı, yürüyüş ile ilgili diğer parametrelerin (yürüyüş hızı, süresi vb.) de araştırılması gerektiği düşünülmektedir. Sağlık için fiziksel aktivite olarak önerilen yürüyüşün günlük toplam adım sayısından daha çok hızı, süresi vb. egzersiz parametrelerinin bireylere özgü olarak hesaplanması ve tavsiye edilmesi gerektiği düşünülmektedir.

\section{Araştırmacıların Katkı Oranı}

Çetin SAYACA: Kavramsallaştırma, araştırma, biçimsel analiz, metodoloji, proje yönetimi, finansman sağlama, veri toplama, yazılım, denetim, doğrulama, istatistiksel analiz, araşatırmanın yazımı, gözden geçirilmesi, düzenlenmesi.

Aykut KARAMAN: Kavramsallaştırma, araştırma, metodoloji, proje yönetimi, finansman sağlama, veri toplama, yazılım, denetim, doğrulama.

\section{Çıkar Çatışması Beyanı}

Yazarlar arasında çıkar çatışması bulunmamaktadır.

\section{Destek/Teşekkür}

Çalışma sırasında hiçbir kurum ya da kişiden finansal destek alınmamıştır. Çalışmaya katılmayı gönüllü olarak kabul eden ve destekleyen katılımcılara tüm yazarlar teşekkür eder.

\section{Kaynaklar}

Arabacı, R. (2008). 15 yaş altı kız ve erkek badmintoncularının fiziksel uygunluklarının karşılaştııılması. Sport Sciences, 3(1), 1-10.

Ardıç, F. (2014). Egzersizin sağlık yararları. Türk Fiz Tıp Rehab $\begin{array}{llll}\text { Derg, } & 60(\text { Özel } & \text { Sayı } & 2 \text { ), }\end{array}$ https://doi.org/10.5152/tttrd.2014.33716

Arslan, E., Aras, D., \& Can, S. (2016). Sporcu ve sedanter kadınlarda günlük enerji harcaması ve fiziksel aktivite düzeylerinin karşılaştırılması. Ankara Üni Spor Bil Fak, 14(1), 53-61. https://doi.org/10.1501/Sporm_0000000284

Arslan, S. S., Alemdaroğlu, İ., Öksüz, Ç., Karaduman, A. A., \& Yılmaz, Ö. T. (2018). Genç bireylerde fiziksel aktivitenin akademik başarı ve depresyon üzerine etkisi. Ergoterapi ve Rehabilitasyon Dergisi, 6(1), 37-42.

Bravata, D. M., Smith-Spangler, C., Sundaram, V., Gienger, A. L., Lin, N., Lewis, R., et al. (2007). Using pedometers to increase physical activity and improve health: A systematic review. JAMA, 298(19), 2296-2304. https://doi.org/10.1001/jama.298.19.2296

Düzgün, I., \& Baltacı, G. (2009). Düzenli spor yapan ve yapmayan adolesanlarda esneklik test sonuçlarının yaş ve cinsiyete bağlı değişimi. Fizyoter Rehabil, 20(3), 184-189.

Erdoğan, A. T., Dal, U., Maraşlıgil, B., \& Beydağı, H. (2016). Üst ekstremite salınımı kısıtlanmasının yürüme enerji tüketimine ve dengeye etkisi. Turk J Phys Med Rehab, 62(4), 329-336. https://doi.org/10.5606/tftrd.2016.66564

Eren, E., Müniroğlu, R. S., \& Özer, U. (2017). Farklı yaş gruplarındaki lisanslı tenisçilerin görsel ve işitsel reaksiyon zamanlarının incelenmesi. Uluslararası Kültürel ve Sosyal Araştırmalar Dergisi (UKSAD), 3(2), 343-352.

Ersoy, İ. C. (2008). Yürüyüş Ve Pilatesin Orta Yaştaki Kadınlarda Vücut Kompozisyonuna Etkisi (Doktora tezi). Dokuz Eylül Üniveristesi Sağlık Bilimleri Enstitüsü, İzmir.

Gribble, P. A., \& Hertel, J. (2003). Considerations for normalizing measures of the Star Excursion Balance Test. Meas Phys Educ Exerc Sci, 7(2), 89-100. https://doi.org/10.1207/S15327841MPEE0702_3 
Guyton, A. C., \& Hall, J. E. (2006). Contraction of skeletal muscle. In W. Schmitt, \& R. Gruliow (Eds.), Textbook of Medical Physiology, (11nd Edition, pp. 75-89) Philadelphia: Elsevier Saunders.

Hazar, F., \& Taşmektepligil, Y. (2008). Puberte öncesi dönemde denge ve esnekliğin çeviklik üzerine etkilerinin incelenmesi. Spormetre Beden Eğitimi ve Spor Bilimleri Dergisi, 6(1), 9-12.

Hultquist, C. N., \& Albright, C. (2005). Comparison of walking recommendations in previously inactive women. Med Sci Sports Exerc, 37(4), 676-683. https://doi.org/10.1249/01.MSS.0000158993.39760.1B

İri, R., Ersoy, A., \& Iri, R. (2010). Yürüyüş egzersizinin bayanların aerobik kapasitelerine ve bazı kan değerlerine etkisi. Uluslararası Insan Bilimleri Dergisi, 7(2), 505-514.

Jordan, A. N., \& Jurca, G. M. (2005). Pedometer indices for weekly physical activity recommendations in postmenopausal women. Med Sci Sports Exerc, 37(9), 1627-1632.

https://doi.org/ 10.1249/01.mss.0000177455.58960.aa

Karaman, Ö. N., Özden, F., Özcanlı, C., \& Mutlu, T. O. (2020). Spor Bilimleri Fakültesindeki Öğrencilerde Denge, Sıçrama Performansı İle Fiziksel Aktivite Düzeyi Arasındaki İlişki. Türkiye Klinikleri Spor Bilimleri Dergisi, 12(2), 163-168. https://doi.org/10.5336/sportsci.2019-72606

Kutlu, M., \& Karadağ, A. (2003). Futbolcularda baskın olan ve olmayan bacakların kuvvet, güç, sürat ve esnekliğinin yeni geliştirilmiş metodlarla belirlenmesi. Gazi Beden Eğitimi ve Spor Bilimleri Dergisi, 8(2), 3342.

Manire, J. T., Kipp, R., Spencer, J., \& Swank, A. M. (2010). Diurnal variation of hamstring and lumbar flexibility. The Journal of Strength \& Conditioning Research, 24(6), 1464-1471. https://doi.org/ 10.1519/JSC.0b013e3181d32e8c

Mantovani, A. M., Duncan, S., Codogno, J. S., Lima, M. C. S., \& Fernandes, R. A. (2016). Different amounts of physical activity measured by pedometer and the associations with health outcomes in adults. Journal of Physical Activity and Health, 13(11), 1183-1191. https://doi.org/10.1123/jpah.2015-0730

McArdle, W. D., Katch, F. L., \& Datch, V. L. (2006). Essentials of exercise physiology (3rd Edition). Philadelphia, PA: Lippincott, Williams \& Wilkins.

Mikkelsson, L. O., Nupponen, H., Kaprio, J., Kautiainen, H., Mikkelsson, M., Kujala, U. M. (2006). Adolescent flexibility, endurance strength, and physical activity as predictors of adult tension neck, low back pain, and knee injury: A 25 year follow up study. Br J Sports Med, 40(2), 107-113. https://doi.org/10.1136/bjsm.2004.017350

Sarıkaya, İ., \& İnan, M. (2014). Patolojik yürüme. TOTBiD Dergisi, 13, 344-350. https://doi.org/10.14292/totbid.dergisi.2014.39

Shaffer, S. W., Teyhen, D. S., Lorenson, C. L., Warren, R. L., Koreerat, C. M., Straseske, C. A., et al. (2013). Ybalance test: A reliability study involving multiple raters. Mil Med, 178(11), 1264-1270. https://doi.org/10.7205/MILMED-D-13-00222
Tamer, K. (2000). Sporda fizyolojik fiziksel performansın ölçülmesi ve değerlendirilmesi. Ankara: Bağırgan Yayımevi.

Tudor-Locke, C., \& Bassett, D. R. (2004). How many steps/day are enough? Preliminary pedometer indices for public health. Sports Med, 34, 1-8. https://doi.org/10.2165/00007256200434010-00001

Tudor-Locke, C., Craig, C. L., Brown, W. J., Clemes, S. A., Cocker, K., Giles-Corti, B., et al. (2011). How many steps/day are enough? For adults. Int J Behav Nutr Phys Act, 8(1), 79. https://do.org/10.1186/1479-5868-8-79

Tunçay, S. U., \& Yeldan, İ. (2013). Kas iskelet sistemi rahatsızlıklarıyla fiziksel inaktivite ilişkili midir? Ağrı, 25(4), 147-155. https://doi.org/10.5505/agri.2013.09825

Welk, G., Differding, J., Thompson, R., Blair, S., Dziura, J., \& Hart, P. (2000). The utility of the Digi-walker step counter to assess daily physical activity patterns. Med Sci Sports Exerc, 32(9), 481-488.

Yıldııı, D. İ., Yıldırım, A., \& Eryılmaz, M. A. (2019). Sağlık çalışanlarında fiziksel aktivite ile yaşam kalitesi ilişkisi. Cukurova Med J, 44(2), 325-333. https://doi.org/10.17826/cumj.451087 